\title{
A spotlight, circular-plot method for counting Brown hares in the hedgerow system
}

\author{
Christophe VERHEYDEN
}

\begin{abstract}
Verheyden C. 1991. A spotlight, circular-plot method for counting Brown hares in the hedgerow system. Acta theriol. 36: $255-265$.

Adjusting the hunting offtake of Brown hare Lepus europaeus (Pallas, 1778) populations requires accurate and reliable density estimates. None of the census techniques currently available is appropriate for large-scale management programs in closed habitats such as the hedgerow system, except the circular-plot method primarily conceived for forest birds. This technique was adapted to hare counts by replacing the original auditive detection by a visual one, and the radius of the plots was the length of a rotating spotlight beam. Other features of the method relied on results concerning census methodology (sampling design, number of counts), hare biology (mobility, activity pattern) and the specific problem of hare counts (detectability, management implications). Density estimates were given with a $\pm 32.6 \%$ accuracy, that was not affected by hare mobility, climatic conditions (though foggy and drizzly nights should be avoided), observer attention, or by the spacing of the points. Due to highly aggregative hare distribution, density intervals are proposed with a method for calculating their limits. Hare detectability was closely related to vegetation height so that our method could be used only when cover is low. The method is reliable, inexpensive, and the sampling design can easily be adjusted to local conditions.
\end{abstract}

Centre d'Etudes Biologiques des Animaux Sauvages, Centre National de la Recherche Scientifique, 79360 Beauvoir-sur-Niort, France

Key words: Lepus europaeus, census method, closed habitats, game management

\section{Introduction}

Since Brown hare populations started to decline in Western Europe (Fraguglione 1975, Barnes and Tapper 1983), large-scale management programs have become increasingly urgent, particularly for adjusting the yearly hunting offtake of wild populations. A good adjustment requires an accurate and reasonably precise knowledge of population density or population size (Andrzejewski and Jezierski 1966). Efficient counting techniques have been developed for open-habitats but not for closed habitats such as the hedgerow system. The numerous hedges surrounding fields prevent the progression of beaters in belt assessments (Pielowski 1969, Pépin and Birkan 1981) and the use of a vehicle-mounted spotlight in line/strip transects (Eltringham and Flux 1971, Flinders and Hansen 1973, Smith and Nydegger 1985), which are the two methods most commonly used. Among other techniques, the track survey method (Hayashi et al. 1966, Hayashi and Komazawa 1971, 1972; Pulliainen and Tunkkari 1987) is 
applicable only in climates with abundant snow; damage assessment (Homolka et al. 1988, Sullivan and Sullivan 1983) is effective only where there are few rabbits (Oryctolagus cuniculus L.) and other grazers; pellet counts (Angerbjorn 1983, Homolka 1985, Krebs et al. 1987) and capture-recapture method (Abildgard et al. 1972, Bresiński 1983, Marcstrom et al. 1989) are too expensive in time when extended over large areas; telemetry method (Boutin 1984) needs a costly equipment, and point counts (Frylestam 1981, Barnes and Tapper 1985), although presenting some interesting features, are mainly designed for open habitats.

Finally, many of the problems of estimating the abundance of hares in closed country are similar to those encountered in studies of birds. I therefore modified the circular-plot method used for forest birds by Blondel et al. (1970) and further improved by Emlen (1971) and Reynolds et al. (1980). The nocturnal feeding habits of hares in open fields (Frylestam 1981, Homolka 1986, Tapper and Barnes 1986) mean that they are easily detected with a spotlight (Barnes and Tapper 1985). The length of the spotlight beam gives the radius of each circular-plot and corresponds to the detection radius of the original method, whereas the visual detection with binoculars replaces the auditive detection of the original method.

A preliminary study conducted in central France from 1983 to 1986 proved the reliability of this technique by direct comparison with an absolute method (Lartiges and Péroux 1987). This paper present the theoretical foundations of this method and its main technical features. Its capacities and cost are evaluated. This census technique has been developed to monitor annual changes in Brown hare populations established in closed habitats where hedges are numerous. Though primarily conceived for game managers this method can be useful in studies of demography or habitat use.

\section{Study area}

The field study was conducted in the Gâtine region (Deux-Sèvres) which is part of the large hedgerow system of northwestern France. The climate is oceanic with $892 \mathrm{~mm}$ annual precipitations, winters are mild and rainy, and summers are dry and fairly hot. The landscape is a mosaic of pastures and cultivated fields of

Table 1. Landscape of the two study sites of western France bocage.

\begin{tabular}{lcc}
\hline Characteristics & Locality A & Locality B \\
\hline Total area (ha) & 2623 & 2563 \\
Hedge length $\left(\mathrm{km} / \mathrm{km}^{2}\right)$ & 18.8 & 8.2 \\
Field size (range in ha) & $1.5-6.6$ & $11.1-20.0$ \\
Crop distribution (\% of cultivated area) & & \\
$\quad$ meadows & 77.5 & 35.3 \\
$\quad$ rye-grass & 4.5 & 23.5 \\
$\quad$ maize & 5.3 & 16.5 \\
$\quad$ cereals & 10.2 & 24.2 \\
$\quad$ other & 2.5 & 0.5 \\
Wooded areas $(\%)$ & 4 & 16 \\
Road system $\left(\mathrm{km} / \mathrm{km}^{2}\right)$ & 3.5 & 3.2 \\
Farms and hamlets $(\mathrm{N})$ & 73 & 62 \\
\hline
\end{tabular}


small size (generally not exceeding $10-15$ hectares) surrounded by tall hedges. Human habitat is composed of small villages and scattered farms connected by a dense track system. Two localities were selected for their different landscape features and agricultural practices (Table 1) representing two poles in the existing types of bocage.

\section{Methods}

The number of sampling points was calculated to combine three conditions: (1) censusing a sufficient area ( 5 to $10 \%$ of the study site); (2) not exceeding a 3-hours census time in order to stay within the maximum activity period of hares (Homolka 1986) and to avoid the weakening of the observer attention; (3) stabilizing the mean value and reducing variability between counts by censusing a minimum area of 130 ha for 15 points as adviced by Frylestam (1981).

Finally, a set of 23 sampling points was established on each of our study site (Fig.1). These plots were disposed in a systematic pattern, $600 \mathrm{~m}$ apart in a grid of isosceles triangles. They corresponded to gateways or gaps between hedges that could easily be reached by car and from where it was possible to light surrounding fields with a hand-held spotlight (100 W, white light, narrow beam). A circle of the spotlight beam was performed from all the gateways and gaps situated in a $15 \mathrm{~m}$ radius around the stopped car. This distance corresponded to the length of a flexible electric-wire connecting the spotlight to the $12 \mathrm{~V}$ battery of the car.

In the open hedgerow system of locality B (Table 1), plot area averaged $8.12 \pm 1.57$ ha for a total sampling area of 186.9 ha. However in the closed hedgerow system of locality A (Table 1) plot area only averaged 5.53 \pm 1.18 ha for a total sampling area of 127.4 ha. These areas were measured from 1:5000 maps; shaded areas

Fig. 1. Two different sampling grids applied on the same locality (site B), showing the distribution of 23 selected sampling stations responding to visibility and accessibility criteria.

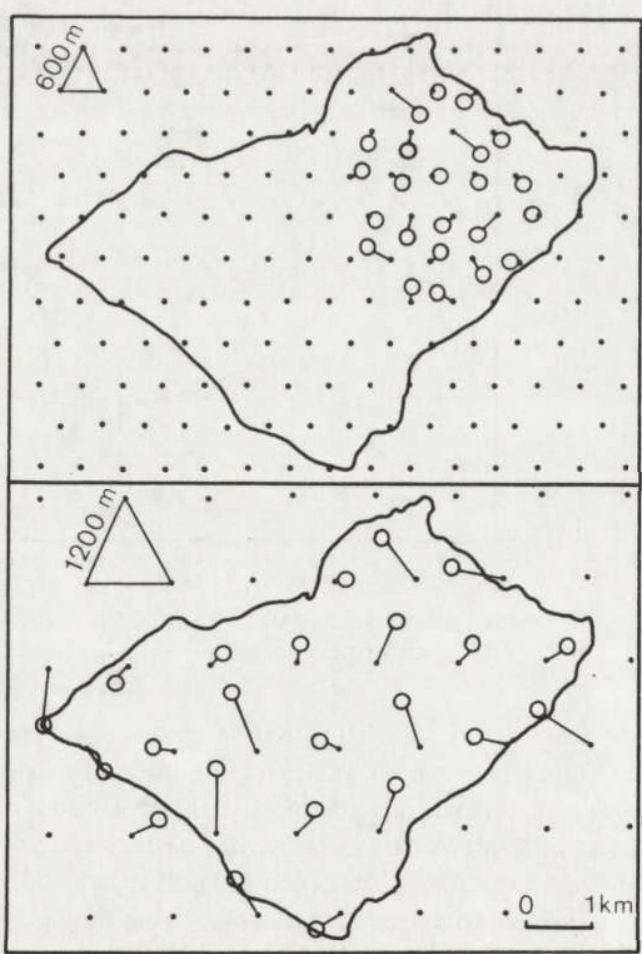

- Theoretical point o Selected point 
created by undulations of the ground and other obstacles were taken into account for correcting unit-areas of each sampling plot.

Since theoretical plots rarely coincided with suitable places, their position was shifted (without creating any overlap between neighbouring points) within a radius of $150.0 \pm 69.5 \mathrm{~m}$ and $169.7 \pm 83.5 \mathrm{~m}$ on locality $\mathrm{A}$ and $\mathrm{B}$ respectively (Fig. 1). With a more open sampling grid $(1200 \mathrm{~m})$ shifting distances were larger, reaching $255.0 \pm 92.6 \mathrm{~m}$ and $270.6 \pm 161.4 \mathrm{~m}$ on locality A and B respectively, no more overlap being created. These distances depended mainly on grid size and road system density.

Counts always started one hour after the sunset and lasted a mean of $193 \pm 16 \mathrm{~min}$. Hares were detected with $8 \times 30$ Swarovski binoculars, either physically when close or by eye-shine farther out. Their location was plotted on a 1:25000 map and their attitude was noted.

Each set of plots was censused four to five times within 15 days in early spring (March/April) of two successive years (1989 and 1990). In 1989 four replicates were completed on locality A in early July (after harvesting of hay and cereal crops) and four others in late August (just after the harvesting of maize and before the opening of hunting season).

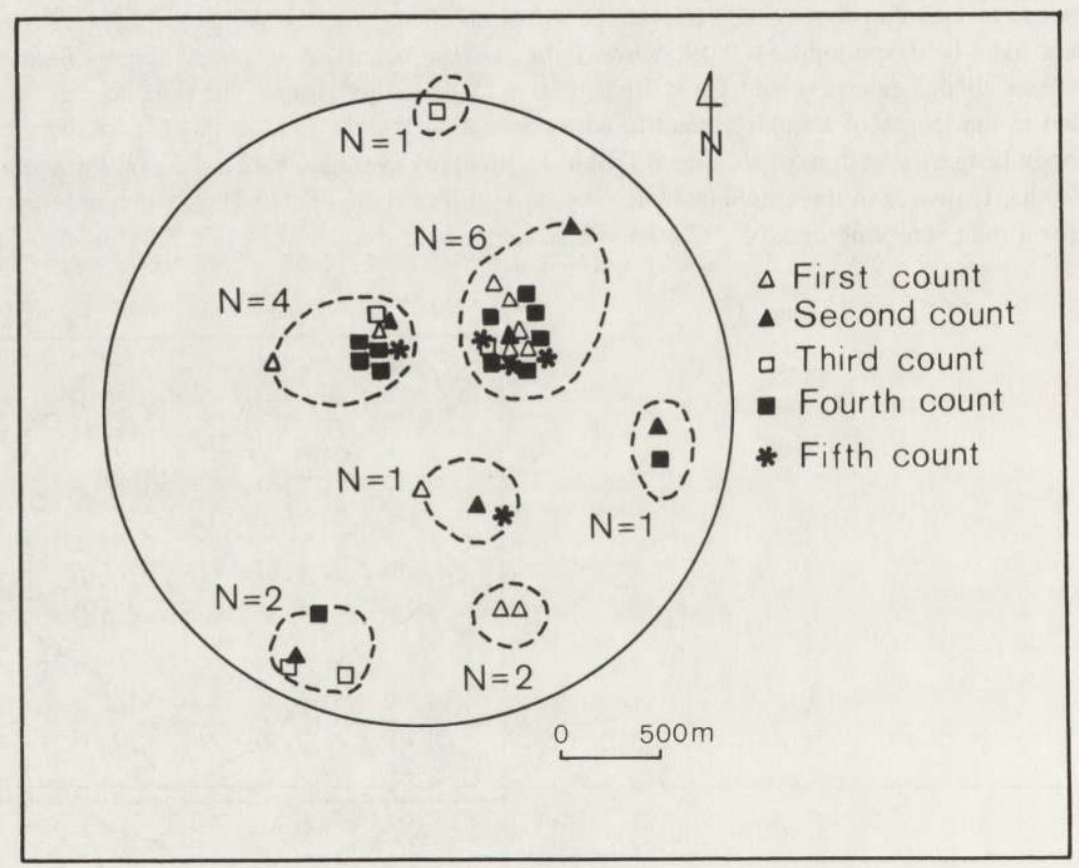

Fig. 2. Cumulated hare locations after a series of five counts, their grouping into positive sectors (presence of hares) and the calculation of maximum hare number on a study site (B), western France, 1989 - 1990.

Crop distribution on sampling area was mapped: it was similar to that of total area, and there was no difference between the two sampling grids of a given locality. Crop height was measured at the beginning of each sampling period to define visibility conditions on the ground. During the early spring of 1990 an additional series of four counts was performed on each site with an increased distance between points $(1200 \mathrm{~m})$, in order to evaluate possible biases due to point spacing.

Lighting time on each plot and driving time between successive plots was noted together with total length. Meteorological data (3-hours survey) was provided by the local station (Niort) and used to test a possible weather influence on hare counts. All hare observations were taken into account, irrespective to the distance, 
since in our field conditions (many hedges, small fields) lighting radius averaged $132.7 \pm 14.2 \mathrm{~m}$ and 160.8 $\pm 15.6 \mathrm{~m}$ on locality A and B respectively, that is well below the effective detection distance $(180 \mathrm{~m})$ determined during the preliminary study (Lartiges and Péroux 1987).

A density interval with a lower and an upper value is given for each density estimate: (1) Minimum densities were calculated from the total number of hares observed in a series of counts, divided by the number of counts in a series and corrected to a standard area (100 ha). These are considered to be underestimates because of the risk of missing animals due to poor visibility conditions, mobility of animals, or excessive distance. (2) Maximum densities (Fig. 2) were calculated by cumulating the maximum numbers of animals seen together on the different sectors during a series of counts; a sector regroups 1-3 plots where hares regularly clustered plus a $300 \mathrm{~m}$ radius around. These maximum numbers are then divided by the total sampling area and corrected to a standard area (100 ha). They are considered to be overestimates because of the risk of counting an animal several times during a series or animals coming from outside the sampling area.

\section{Results and discussion}

\section{Foundations of the method}

A fixed-plot sampling design was adopted fo three reasons. Firstly, the original method was conceived for tall and dense vegetation and uneven terrain (Blondel et al. 1970, Reynolds et al. 1980, Bollinger et al. 1988), and these basic problems of visibility and accessibility also are the main features of the hedgerow system. Secondly, stationary observers have been demonstrated to have lower probabilities of missing animals (still reduced by the use of binoculars) than moving ones (Reynolds et al. 1980), and movements of the observer can create biases (Emlen 1971, Ramsey and Scott 1978, Burnham et al. 1980). Thirdly, Burnham et al. (1980) recommended the avoidance of line transects for highly mobile species (such as hares), and Granholm (1983) suggested the use of large circular-plots and short count periods to reduce bias resulting from animal movements.

The risk of counting a hare twice was excluded by regularly spacing the sampling points at a minimum distance of $600 \mathrm{~m}$ so that there was no overlap between lighting areas of neighbouring points (the spotlight beam was effective up to $250 \mathrm{~m}$ ). There was no risk that an animal move from an enlighted point to an other because hares are known to be undisturbed by a spotlight (Barnes and Tapper 1985), even when rotating slowly from a car (Broekhuizen and Maaskamp 1980). Statistically, such a systematic pattern is particularly recommanded (Frontier 1983) for distributing small sampling stations (like ours) and is well designed for heterogeneous habitats (like the hedgerow system).

The main census period (March/April) was chosen because at that time hare shooting is over (population undisturbed), vegetation cover is low (good visibility), cattle are absent (see their disturbing effect on hares in Frylestam 1976) and the hares present constitute the breeding stock (Broekhuizen and Maaskamp 1981). The choice of other counting periods was dependent on the cover height that fluctuate widely in relation to cattle grazing and agricultural practices.

Hours of counts were chosen to coincide with the period of maximum hare activity (Homolka 1986), used for night counts in previous studies (Frylestam 1980, 1981).

The choice of density intervals rather than precise values seemed more appropriate to characterize a population with such a highly aggregative distribution as hares (Jezierski 1972, Monaghan and Metcalfe 1985, Barnes and Tapper 1985). The area of sectors used for the 
calculation of maximum densities took into account the mean radius of a hare home-range (Broekhuizen and Maaskamp 1982, Homolka 1985).

\section{Accuracy of the method and factors affecting it}

Differences in hare numbers occurred between successive counts of a series, and this independently of year, season, locality and grid size (Table 2). They were not negligible, with a mean coefficient of variation of $32.6 \%$ for 26 spring counts, compared with $26.8 \%$ for 25 spring counts by Barnes and Tapper (1985) and $13.3 \%$ for 27 spring counts by Frylestam (1981), these two authors using a spotlight method on fixed plots. Nevertheless, estimates remained within the $95 \%$ confidence interval.

Weather conditions are suspected to have an important influence on population estimates based on night counts since Barnes and Tapper (1985) found a significant relationship between hare estimates and air temperature. In this study I found no correlation with atmospheric

Table 2. Hare numbers and density estimates (hare $/ \mathrm{km}^{2}$ ) obtained from 34 spotlight counts on two study sites, western France, $1989-1990$. G1 = a distance of $600 \mathrm{~m}$ between plots, G2 = a distance of $1200 \mathrm{~m}$ between plots.

\begin{tabular}{lcccccc}
\hline Site & Period & $\begin{array}{c}\text { Counts } \\
(\mathrm{N})\end{array}$ & $\begin{array}{c}\text { Grid } \\
\text { size }\end{array}$ & $\begin{array}{c}\text { Hare numbers } \\
(x \pm \mathrm{SD})\end{array}$ & \multicolumn{2}{c}{ Hare density } \\
A & & & & & Max \\
\hline & $03 / 89$ & 5 & G1 & $6.4 \pm 1.7$ & 5.0 & 10.2 \\
& $07 / 89$ & 4 & G1 & $5.7 \pm 2.4$ & 4.5 & 9.4 \\
& $08 / 89$ & 4 & G1 & $4.0 \pm 0.0$ & 3.1 & 7.1 \\
& $03 / 90$ & 4 & G1 & $2.7 \pm 0.8$ & 2.1 & 4.7 \\
& $03 / 90$ & 4 & G2 & $2.7 \pm 0.8$ & 2.1 & 4.7 \\
B & $03 / 89$ & 5 & G1 & $7.6 \pm 2.8$ & 4.1 & 9.1 \\
& $03 / 90$ & 4 & G1 & $2.5 \pm 1.1$ & 1.3 & 3.7 \\
& $03 / 90$ & 4 & G2 & $1.7 \pm 0.4$ & 0.9 & 1.6 \\
\hline
\end{tabular}

pressure, mean windspeed, total precipitations nor phase of the moon. Moreover, I did not find the relation again with air temperature so that the correction factor used in the previously cited study was unnecessary. Since rapid changes in atmospheric pressure were found to produce low estimates (Barnes and Tapper 1985) I tested such an effect on my results: I found no direct relation although $75 \%$ of under-mean estimates $(n=16)$ were obtained during a pressure decrease. On the other hand, the two lowest values for a given period (site B, spring 1989) corresponded to the nights with strongest winds ( $10 \mathrm{~m} / \mathrm{s}$ vs $4.6 \mathrm{~m} / \mathrm{s}$, mean value), and the highest estimates of the same period were obtained with the highest rainfalls ( $18 \mathrm{~mm}$ vs 1 $\mathrm{mm}$, mean value for 11 days).

These results indicate that climatic conditions certainly have some influence on population estimates, which is not surprising since activity patterns of this species have been demonstrated to be strongly related to weather (Jezierski 1973, Frylestam 1986).

Hares are very mobile (Broekhuizen and Maaskamp 1981, Homolka 1985) and mobility of animals is known to be an important source of bias in density estimates (Burnham et al. 
1980, Granholm 1983, Verner and Ritter 1985), thus I tried to test the influence of this factor on my counts. A mobility index Im was determined such as $\operatorname{Im}=(\mathrm{Nm}-\mathrm{Ni}) / \mathrm{Ni}$, where $\mathrm{Nm}$ is the cumulated number of plots where hares had been noted during a series of counts, and $\mathrm{Ni}$ is the number of plots where hares were seen the first night of a series. For a non-mobile species, where individuals are always seen on the same plots, the number of positive plots is constant $(\mathrm{Nm}=\mathrm{Ni})$ and the mobility index is equal to zero. This is the case for rabbits, that were also counted during this study and for which a very low value of mobility $(\operatorname{Im}=0.46)$ was obtained. For hares, a significantly greater value $(\operatorname{Im}=1.56, t=3.05, p<0.02)$ was obtained, but there was a poorly significant correlation between the coefficients of variation and the corresponding mobility index $(r=0.531, t=1.77, p=0.10)$, indicating that hare mobility has little influence on the observed variability.

Since the observer was always the same person and plots were always censused following the same order, the only possible risk of bias that remains is the time spent counting on a plot

Table 3. Time allocation between counting and driving operations during 34 night counts of hares at different seasons on two localities of western France, 1989-1990. G1 and G2, see Table 2.

\begin{tabular}{lcccccc}
\hline Site & Period & Grid size & $\begin{array}{c}\text { Counting } \\
\text { time } \pm \text { SD } \\
(\mathrm{min})\end{array}$ & $\begin{array}{c}\text { Driving } \\
\text { time } \pm \text { SD } \\
(\mathrm{min})\end{array}$ & $\begin{array}{c}\text { Driving } \\
\text { speed } \\
(\mathrm{km} / \mathrm{h})\end{array}$ & $\begin{array}{c}\text { Total } \\
\text { time } \pm \text { SD } \\
(\mathrm{min})\end{array}$ \\
\hline A & $03 / 89$ & G1 & $114 \pm 6$ & $83 \pm 11$ & 14.4 & $197 \pm 16$ \\
& $07 / 89$ & G1 & $103 \pm 4$ & $70 \pm 5$ & 17.1 & $172 \pm 7$ \\
& $08 / 89$ & G1 & $110 \pm 1$ & $62 \pm 4$ & 19.3 & $172 \pm 3$ \\
& $03 / 90$ & G1 & $122 \pm 4$ & $58 \pm 4$ & 20.7 & $181 \pm 7$ \\
& $03 / 90$ & G2 & $125 \pm 8$ & $97 \pm 7$ & 30.9 & $222 \pm 15$ \\
B & $03 / 89$ & G1 & $120 \pm 6$ & $79 \pm 8$ & 15.9 & $200 \pm 7$ \\
& $03 / 90$ & G1 & $127 \pm 6$ & $65 \pm 4$ & 19.4 & $194 \pm 8$ \\
& $03 / 90$ & G2 & $125 \pm 7$ & $81 \pm 6$ & 29.6 & $206 \pm 13$ \\
\hline
\end{tabular}

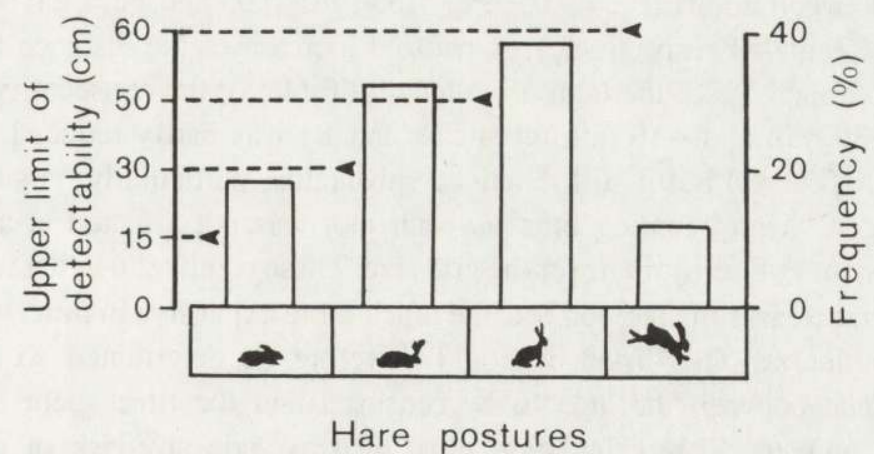

Fig. 3. Observed frequency of different hare postures and their respective upper limits of detectability according to vegetation height. 
and the driving time between successive plots. Total duration of a count was very close (193 $\mathrm{min}$ ) to the predicted value ( $180 \mathrm{~min})$ and showed little $( \pm 16 \mathrm{~min})$ variability (Table 3$)$. Driving time tended to be shorter as the driver got used to the circuit (Table 3), but counting time remained remarkably constant $(118 \pm 7 \mathrm{~min})$. It was not affected by observer habituation, nor by plot area but was slightly longer (Table 3 ) when hares were more numerous $(t=4 \mathrm{~min}$ $48 \sec$ for $\mathrm{n}$ hares/plot, $\mathrm{N}=391$ and $\mathrm{t}=6 \min 33 \sec$ for $\mathrm{n}>2$ hares/plot, $\mathrm{N}=23$ ).

\section{Conditions of use}

V i s ibility c o ndition s: During these night counts, hares were not always observed in the same attitude, though generally feeding or scanning (Fig. 3). Each attitude corresponds to a certain height from the ground so that when vegetation is higher than these limits hares could not be detected (Fig. 3). It means that hare detectability is closely related to vegetation height, which could vary widely depending on the type of crop and time of the year. During this study counts made after spring could be performed only on site A where meadows $(<30 \mathrm{~cm})$ predominate ( $77 \%$ of the sampling area), but they were unusable on site B where $>64 \%$ of the sampling area was covered by tall cultures $(>50 \mathrm{~cm})$ such as maize, cereals or rye-grass (Table 1). So, counts can be made only in habitats where hare detectability is optimal, i.e. where the major part of the sampling area is covered by short vegetation. On a given favourable habitat (site A), after-spring counting periods were chosen in relation to agricultural operations: a series could be performed in early July after the harvesting of rye-grass and cereal crop give visibility on an additionnal $15 \%$ of the area. Another series could be done in late August when the harvesting of maize allowed an additionnal area of 5\% to be censused. So, even on a favourable habitat, these hare counts should be restricted to the periods when agricultural practices determine a good visibility on the major part $(>90 \%)$ of the sampling area.

P l a c ing the po in ts: When the distance between sampling stations was increased from $600 \mathrm{~m}$ to $1200 \mathrm{~m}$, the mean numbers of hares counted (Table 2) were not statistically different $(t=0, p>0.90$ and $t=1.37, p>0.20$ for locality A and B respectively) nor was the variability between nights $(\mathrm{Fc}=1.0<\mathrm{Ft}=15.4, p\rangle 0.05$ and $\mathrm{Fc}=2.6\langle\mathrm{Ft}=15.4, p\rangle$ 0.05 for locality A and B respectively). A twofold increase of the distance between stations induced a twofold increase of the total drive length (Table 3); the consecutive increase of the driving time $(+39 \mathrm{~min}$ and $+16 \mathrm{~min}$ on site $\mathrm{A}$ and $\mathrm{B})$ was partly reduced by an increased driving speed $(+10 \mathrm{~km} / \mathrm{h})$ but it still remained substantial, particularly on site A where road system was larger. Mean counting time on each plot was not affected at all and remained remarkably constant ( \pm 8 secs) whatever the grid size. These results show that when the distance between stations increases the method became much more expensive in time, without changing the resulting estimates. The distance should therefore be determined so as to ensure an acceptable balance between the area to be censused and the time spent driving (and the associated fuel budget). This calculation must also exclude any risk of overlap between neighbouring points, which is related to habitat structure and the lighting distance, 


\section{Reliability of the method}

The reliability of the method was not tested in this work because it has been previously validated during the preliminary study that was conducted in Central France from 1983 to 1986: when numbers were corrected in relation to distance, there was a significant linear correlation $(r=0.975, p<0.001, \mathrm{n}=6)$ between hare estimates obtained by a similar method ( 6 series of four to seven night counts on 36 points 600 to $800 \mathrm{~m}$ apart) and those of an absolute method ( 6 counting beats on a 480 ha area). Moreover, numbers counted by the two methods were virtually the same (Lartiges and Péroux 1987). In this work I did not have to correct for distance since all observations were beyond the effective distance. These results are very close to those of Barnes and Tapper (1985) when they tested their spotlight method against hare shooting on a 1400 ha area of England and found a strong correlation between the two methods. Frylestam (1981) also found very close results between his spotlight counts on fixed plots and flushing of hares by the mean of a trailing line dragged between two cars (difference $<10 \%$ ) on a 196 ha area of southern Sweden.

\section{Conclusions}

The method presented here meets all circular-plot assumptions, without serious violations, and is easily conducted in the hedgerow system, contrary to other classical methods. It gives reliable estimates of hare density since it has been validated against absolute methods, and provides a reasonably accurate measure of population density, comparable to that of other widespread methods. It requires little time, personel and equipment, and can easily be planed and conducted by an untrained person. Sampling design (number and distribution of points) can be adapted according to prevailing environmental conditions (hedge and road system density) but it is not applicable in all habitats. The method has not been validated in open habitats and is not suited to forest habitats. Counts cannot be done at any time of the year and counting periods must be fixed depending on the vegetation height in fields. The method is sensitive to visibility conditions, thus foggy and drizzly nights should be avoided. Field data are easy to analyze and can be used for assessing differences between hare populations and their changes over time. These informations allow the hunting offtake of hares to be calculated and adjusted to wild populations, and could also correspond to research preoccupations.

Aknowledgements: I am much indebted to R. Péroux for kindly providing me unpublished data and useful methodological advices. I thank technicians of the "Fédération des Chasseurs des Deux-Sèvres" (Regional Game Management Service) for their help in field organization and the numerous persons who assisted me in spotlight manipulation along successive nights. I am grateful to Dr. P. Duncan for helpful comments on the manuscript and C. Moinard for improving the English. This work was funded by a grant from the "Office National de la Chasse" (National Game Agency).

\section{References}

Abildgard F., Andersen J. and Barndorff-Nielson O. 1972. The hare population (Lepus europaeus Pallas) of Illumo Island, Denmark. A report on the analysis of the data from 1957 - 1970. Dan. Rev. Game Biol. 6: $1-32$.

Andrzejewski R. and Jezierski W. 1966. Studies on the european hare. XI. Estimation of population density and attempt to plan the yearly take of hares. Acta theriol. 11: $433-448$. 
Angerbjorn A. 1983. Reliability of pellet counts as density estimates of mountain hares. Fin. Game Res. 41: $13-20$.

Barnes R. and Tapper S. 1983. Why we have fewer hares. Game Cons. Ann. Rev. 82: $51-61$.

Barnes R. and Tapper S. 1985. A method for counting hares by spotlight. J. Zool., Lond. 206: 273 - 276.

Blondel J., Ferry C. and Frochot B. 1970. La méthode des indices ponctuels d'abondance (I.P.A.) ou des relevés d'avifaune par "stations d'écoute". Alauda 38: 55 - 71 .

Bollinger E. K., Gavin T. A. and McIntyre D. C. 1988. Comparison of transects and circular-plots for estimating bobolink densities. J. Wildl. Manage. 52: 777 - 786.

Boutin S. 1984. Home-range size and methods of estimating snowshoe hare density. Acta Zool. Fenn. 171: $275-278$.

Bresiński K. 1983. The effect of some habitat factors on the spatial distribution of a hare population during winter. Acta theriol. 28: $435-441$.

Broekhuizen S. and Maaskamp F. 1980. Behaviour of does and leverets of the European hare (Lepus europaeus) whilst nursing. J. Zool., Lond. 191: $487-501$.

Broekhuizen S. and Maaskamp F. 1981. Annual production of young in European hares (Lepus europaeus) in the Netherlands. J. Zool., Lond. 193: 499 - 516.

Broekhuizen S. and Maaskamp F. 1982. Movement, home-range and clustering in the European hare (Lepus europaeus Pallas) in the Netherlands. Z. Säugetierk. 44: $22-32$.

Burnham K. P., Anderson D. R. and Laake J. L. 1980. Estimation of density from line transect sampling of biological populations. Wildl. Monogr. 72: 1-202.

Eltringham S. K. and Flux J. E. C. 1971. Night counts of hares and other animals in East Africa. Afr. Wildl. J. 9: $67-72$.

Emlen J. T. 1971. Population density of birds derived from transect counts. Auk 88: $323-342$.

Flinders J. T. and Hansen R. M. 1973. Abundance and dispersion of Leporids within a shortgrass ecosystem. J. Mammal. 2: 287 - 291.

Fraguglione D. 1975. La régression du lièvre commun en Europe Occidentale. Proc. XIIth. Congr. Game Biol., Lisbon.

Frontier S. 1983. Stratégies d'échantillonnage en écologie. Collection d'écologie 17. Masson \& P.U.L., eds. Québec: 1 - 494.

Frylestam B. 1976. Effect of cattle grazing and harvesting of hay on density and distribution of an european hare population. [In: Ecology and management of European hare populations. Z. Pielowski and Z. Pucek, eds]. Polish Hunting Ass., Warsaw: 199 - 203.

Frylestam B. 1980. Reproduction in the European hare in southern Sweden. Hol. Ecol. 3: $74-80$.

Frylestam B. 1981. Estimating by spotlight the population density of the European hare. Acta theriol. 26: $419-423$.

Frylestam B. 1986. Agriculture land use effects on winter diet of European hares in southern Sweden. Mammal Rev. 16: $157-162$.

Granholm S. L. 1983. Bias in density estimates due to movement of birds. Condor 85: 243 - 248 .

Hayashi C., Isida M. and Oishi Y. 1966. Estimation of size of mobile population. I. Sample survey for the estimation of the size of hares in a district. Proc. Inst. Statist. Math. 14: $63-86$.

Hayashi C. and Komazawa I. 1971. Estimation of size of mobile population.V. Estimation of trace length of a hare in one night by random selected trace (RST) method and computer simulation. Proc. Inst. Statist. Math. 19: $14-27$.

Hayashi C. and Komazawa I. 1972. Estimation of size of mobile population.VIII. Bayesian estimation in RST -method based on the observed number of randomly selected points. Proc. Inst. Statist. Math. 20: 117 120.

Homolka M. 1985. Spatial activity of hares (Lepus europaeus). Folia zool. 34: 217 - 226.

Homolka M. 1986. Daily activity pattern of the European hare (Lepus europaeus). Folia zool. 35: $33-42$.

Homolka M., Zejda J., Bauerova Z., Kozena I. and Nesvadbova J. 1988. Importance of windbreaks for Lepus europaeus and Capreolus capreolus. Folia zool. 37: 17- 25. 
Jezierski W. 1972. Elements of the space structure of European hare (Lepus europaeus Pallas, 1778) population. Ekol. pol. 42: $593-607$.

Jezierski W. 1973. Environmental conditioning of the space structure and shyness in hares (Lepus europaeus Pallas, 1778). Ekol. pol. 21: 1 - 12.

Krebs C. J., Scott-Gilbert B., Boutin S. and Boonstra R. 1987. Estimation of hare population density from turd transects. Can. J. Zool. 65: $565-567$.

Lartiges A. and Péroux R. 1987. Etudes sur la démographie des populations chassées de lièvres à densités faibles à moyennes. Office National de la Chasse, Station du Massif Central, Rapport interne, $1-22$.

Marcstrom V., Keith L. B., Engren E. and Cary J. R. 1989. Demographic responses of arctic hares (Lepus timidus) to experimental reduction of red foxes (Vulpes vulpes) and martens (Martes martes). Can. J. Zool. 67: $658-668$.

Monaghan P. and Metcalfe N. B. 1985. Group foraging in wild brown hares: effects of resource distribution and social status. Anim. Behav. 33: 993 - 999.

Pépin D. and Birkan M. 1981. Comparative total and strip census estimates of hares and partridges. Acta Oecol. 2: $151-160$.

Pielowski Z. 1969. Belt assessment as a reliable method of determining the numbers of hares. Acta theriol. 14: $133-140$.

Pulliainen E. and Tunkkari P. S. 1987. Winter diet, habitat selection and fluctuation of a mountain hare (Lepus timidus) population in Finnish forest lapland. Hol. Ecol. 10: 261 - 267.

Ramsey F. L. and Scott J. M. 1978. Use of circular plot surveys in estimating the density of a population with Poisson scattering. Tech. Rep., 60. Dept. of Stat., Oregon State Univ., Corvallis.

Reynolds R. T., Scott J. M. and Nussbaum R. A. 1980. A variable circular-plot method for estimating bird numbers. Condor 82: 309-313.

Smith G. W. and Nydegger N. C. 1985. A spotlight, line-transect method for surveying jack-rabbits. J. Wildl. Manage. 49: $699-702$.

Sullivan T. P. and Sullivan D. S. 1983. Use of index lines and damage assessment to estimate population densities of snowshoe hares. Can. J. Zool. 61: 163-167.

Tapper S. and Barnes R. 1986. Influence of farming practice on the ecology of brown hare (Lepus europaeus). J. appl. Ecol. 23: $39-52$.

Verner J. and Ritter L. V. 1985. A comparison of transects and point counts in oak-pine woodlands of California. Condor 87: 47 - 68 .

Received 10 April 1991, accepted 23 July 1991. 